\title{
UMP and DRB-HICOM: A Mismatch of Expectations
}

\author{
Nabila Abdul Malek*, Normah Othman \\ Centre for Modern Languages \& Human Sciences, Universiti Malaysia Pahang, Lebuhraya Tun Razak, 26300 Gambang, Kuantan, Pahang, \\ Malaysia \\ bellamalek11@yahoo.com,normah_othman@yahoo.com
}

\begin{abstract}
A survey in the form of a questionnaire was conducted on 40 academicians teaching at the Mechanical Engineering Faculty, Universiti Malaysia Pahang. The survey was to find out the academicians' opinions about their faculty's relationship with the DRB-HICOM industry. The survey was also to find out whether their job has any significant effect on the students' performance at the automotive industry. The results show that there is mismatch between the DRB-HICOM's and UMP's expectations on the students' overall performance in the industry. This paper discusses the mismatch.
\end{abstract}

Keywords University-Industry Partnership, Mechanical Engineering, Mechanical Education, Automotive Engineering, Manufacturing Engineering

\section{Introduction}

The university-industry partnership has become very important especially in advancing both academic and industry knowledge. University plays an important role in producing potential and skilled labour force for the industry. Thus knowing the industry needs and requirement can help the university to outline relevant course content for the students. In addition, according to Normah (2011), this collaboration helps the university to encroach more funds from the industry and not relying solely on the government. Moreover, as stated by Jones (2012), the university benefits through the access to cutting-edge scientific equipment not always available in university labs. University also enhance opportunities to find future employment for undergraduate and graduate students through this university-industry partnership. On the other hand, according to Jones (2012), traditionally, industry sought partnerships with universities as a means to identify and train future employees, for the design and development of innovative processes and potential products and also the need of innovative ideas to ensure their profits. The overall objective is to encourage contribution to the general knowledge base and to develop good working relationship with the industries.

\section{Research Objectives}

This study embarks on the following objectives:

1. To assess the current condition of UMP, in relation to

* Corresponding author:

bellamalek11@yahoo.com(Nabila Abdul Malek)

Published online at http://journal.sapub.org/economics

Copyright (C) 2012 Scientific \& Academic Publishing. All Rights Reserved auto engineering and manufacturing engineering.

2. To assess the current course content taught at the Mechanical Engineering Faculty in UMP.

3. To make recommendation based on the research, and find a long-term partnership between DRB-HICOM and UMP.

\section{Methodology}

This research employed a survey in the form of questionnaire. The questionnaire was distributed to 40 of the academic staffs at the Mechanical Engineering Faculty of UMP. The data obtained from this survey were quantitative data in the form of graphs and table. The data were analysed manually by the researchers.

\section{Results and Discussion}

The questionnaire was divided into 3 sections; section A, section $\mathrm{B}$ and section $\mathrm{C}$. In section $\mathrm{A}$, the respondents were asked questions related to the course content evaluation and also on industrial-partnership evaluation; case of DRB-HICOM. On the other hand, in section B, the respondents need to give their on-the-spot belief on certain statements using the Likert Scale. Lastly, in section $C$, the respondents need to give their opinion on the given questions.

The analyses of the questions are as shown in the next pages:

\subsection{Section A}

\subsubsection{Course Content Evaluation}

Does improvement need to be made for your subject in order to suits the industry needs? If your answer is YES 
please give your reason.

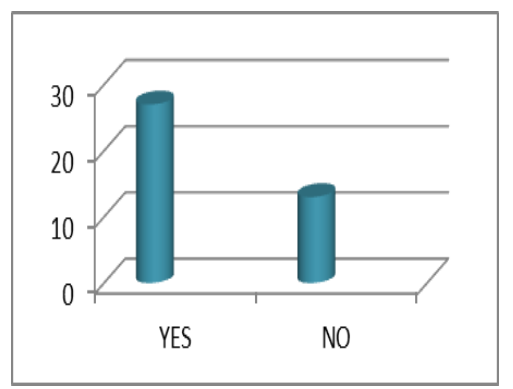

Figure 1. The respondents agree that improvement need to be made for their subjects

It can be concluded that $67.5 \%$ of the respondents agree that improvement need to be made for their subjects. This means that more than half of the respondents feel that improvement in the content of their subjects is important to suits the industry needs. Most of them believe that the syllabus should be more focus on topics that are relevant with the industry and follow the latest technology development. Moreover, the academicians believe that UMP should be updated with the industry requirement and current practice. Most of all they prefer to have more hands on activity rather than theories and this requires sufficient lab facilities. In short, it is hope that the university can improve the lab facilities so that more practical training can be provided to the students so that they can apply their knowledge.

Lack of facilities makes it difficult for students to understand the actual environment in the industry. If your answer is YES please give your reason.

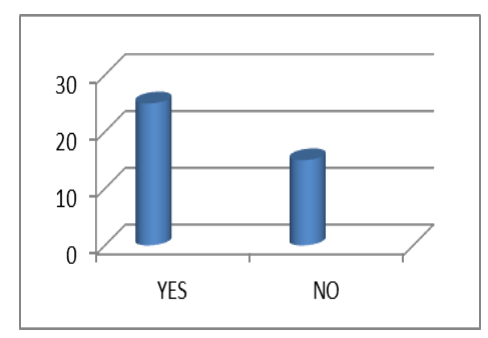

Figure 2. The respondents feel that enough facilities are very important

It can be concluded that $62.5 \%$ of the respondents feel that enough facilities are very important because it can expose the processes involve in the real industry to the students and it helps the students to visualize the actual working environment prior to their industrial practical. Students' lack of experience on the real industrial environment will not perform well during their practical because they do not know how to apply their knowledge. Thus, hands on activities and experiences are vital before they joint the industry.

\subsubsection{Industrial - Partnership Evaluation. Case of DRB- Hicom}

From your previous experiences, is DRB-Hicom satisfied with the work of FKM's students? Please give your reason.Does improvement need to be made for your subject in order to suits the industry needs? If your answer is YES please give your reason.

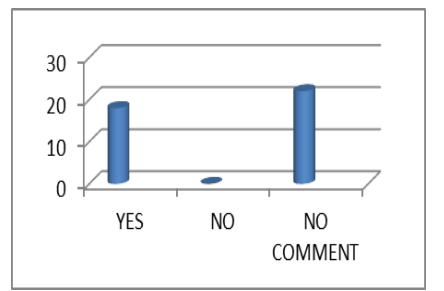

Figure 3. The respondents agree that DRB-HICOM is satisfied with our students work

Based on the findings, it can be concluded that $45 \%$ of the respondents agree that DRB-HICOM is satisfied with our students work because most of the students are hired to work in DRB-HICOM after they graduated and they are doing fine there. Until now, there are no complaints about the quality of FKM students' work. This proves that as a technical university, UMP is capable of providing a very good future engineer in automotive field.

DRB-Hicom has contributed expertise and technology in the automotive and manufacturing engineering to UMP. Please give your reason.

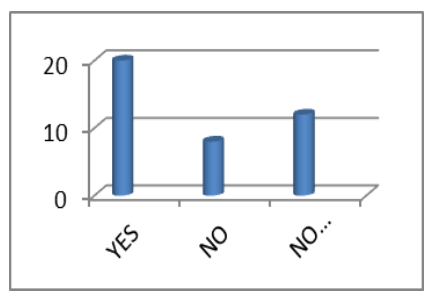

Figure 4. The respondents agree that DRB-HICOM contributed expertise and technology in the automotive and manufacturing engineering to UMP

It can be concluded that $50 \%$ of the respondents agree that DRB-HICOM contributed expertise and technology in the automotive and manufacturing engineering to UMP. However, most of the contributions are in the form of collaboration through research and lab qualities but not on subject requirement. On the other hand, through this collaboration, industries may benefit from getting their manufacturing issues and problems resolved as well as research ideas explored and conducted, without having to engage many researchers full time on their own.

FKM students get proper exposures related to their field of study during their industrial practical in DRB-Hicom. If your answer is NO please give your reason.

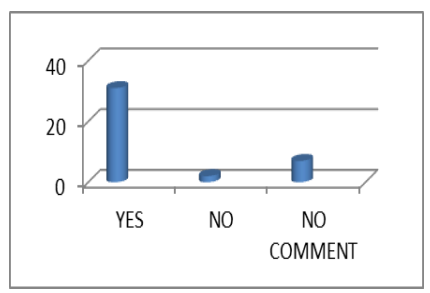

Figure 5. The respondents agree that FKM students get proper exposures related to their field of study during their industrial practical in DRB-Hicom

It can be concluded that $77.5 \%$ of the respondents agree that FKM students get proper exposures related to their field of study during their industrial practical in 
DRB-Hicom. However, there are $5 \%$ of the respondents disagree and the reasons given are quite rational because the students are only given 12 weeks of industrial training and usually there are nothing much they can do during that 12 weeks. Most of them are just given easy job scope and got the chance to feel the working environment only.

\subsection{Section B}

Your subject is in line with industry requirements.

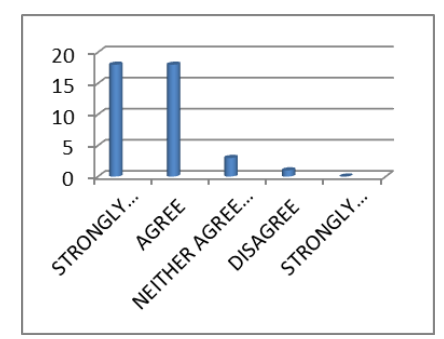

Figure 6. The respondents agree that the subject they taught is in line with the industry

Based on Figure 6, it can be concluded that 36 of the respondents $(90 \%)$ strongly agree and agree that the subject they taught is in line with the industry. This means that most of the academic staffs agree that UMP provides sufficient mechanical engineering knowledge to it students.

Your subject content has more theories than practical.

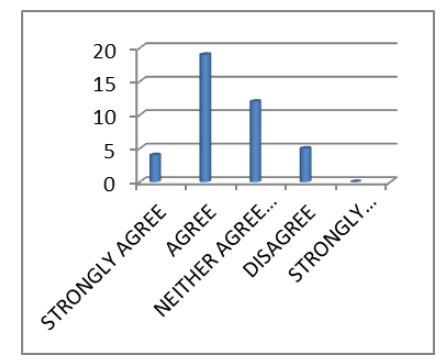

Figure 7. The respondents agree that the course content provided in Faculty of Mechanical Engineering of UMP focus more on theories rather than practical

Based on Figure 7, it can be concluded that the course content provided in Faculty of Mechanical Engineering of UMP focus more on theories rather than practical because 4 of the respondents $(10 \%)$ strongly agree and 19 of the respondents $(47.5 \%)$ agree with the statement. In total, $57.5 \%$ of the respondents support this statement.

Frequent practice is necessary for the students to be prepared for their industrial practical.

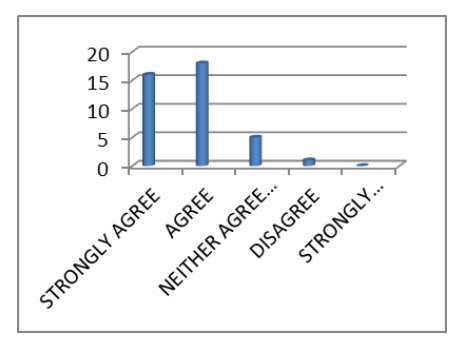

Figure 8. The respondents support the need of frequent practice before the students go for their industrial practical
Based on Figure 8, it can be concluded that 16 of the respondents (40\%) strongly agree and 18 of them (45\%) agree with the statement. This means that $85 \%$ of the academic staffs in Faculty of Mechanical Engineering UMP support the need of frequent practice before the students go for their industrial practical.

More facilities and equipment are needed to help the students to fit the industry requirements.

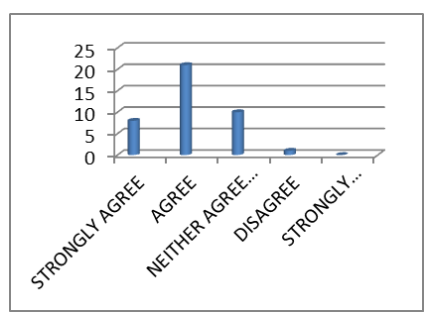

Figure 9. The respondents agree that sufficient facilities and equipment are needed to help the students to fit the industry requirements

Based on Figure 9, it can be concluded that sufficient facilities and equipment are vital in order to help the students to fit the industry requirements. This statement supported by $72.5 \%$ of the academic staffs in Faculty of Mechanical Engineering.

Collaboration between UMP and industries enable the sharing of expertise and technology occurs.

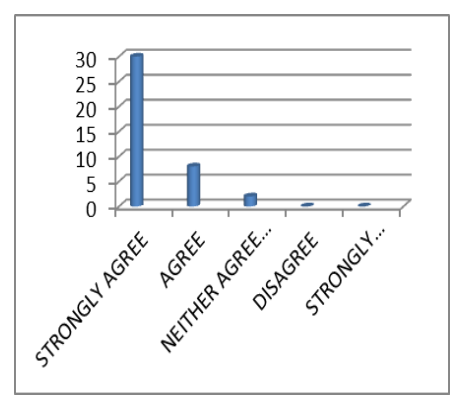

Figure 10. The respondents agree that the collaboration will enable the sharing of expertise and technology occurs

Based on Figure 10, it can be concluded that 30 of the respondents (75\%) strongly agree and 8 of them (20\%) agree with this statement. It shows that $95 \%$ of the academic staffs supported the idea that the collaboration will enable the sharing of expertise and technology occurs.

\subsection{Section $C$}

In your opinion, what are the strengths or weaknesses of your subject in line with the industry?

From all the given answers, it can be concluded that most of the academic staffs believe that the subject they taught are fundamentals for the students and it is useful for them when they graduated. On the negative side, the main concerns of the academic staffs related to the subject they taught are lack of practical skills and not able to give exposure to new technology implies in industry nowadays.

What are the barriers or challenges to teach your subject?

From all the given answers, it can be concluded that the main challenges the respondents faced are the students' 
attitude, lack of fundamental knowledge in mathematics and physics and the students are not able to relate and apply the skills due to lack of practical training.

\section{Conclusions and Recommendations}

The results from the questionnaire show that the current course content taught at the Mechanical Engineering Faculty in UMP is sufficient for the students and in line with the industry needs. However, some improvement is needed to make sure that the syllabus is not out-dated. In addition, the university should provide more facilities for practical purpose to enhance the students understanding of the subject. Sufficient facilities and equipment can give exposure to the students on the processes involve in the real industry and it helps the students to visualize the actual working environment prior to their industrial practical.

As mentioned by Blaug, Chien, \& Shuster (2004), the relationship between universities and industry is multifaceted, encompassing exchanges of knowledge, expertise, working culture and money. Looking at the current condition of UMP, in relation to auto engineering and manufacturing engineering, it is agreed that the university have a long way to established in automotive and manufacturing engineering field because we are still new and it is hoped that the collaboration between UMP and DRB-HICOM will enable the sharing of expertise and technology that will greatly benefits both parties. However, we believe that UMP is doing well in relation to automotive and manufacturing field in the time being because people from the industries are starting to know and acknowledge the graduates from UMP.

As for recommendation, it is suggested that the university and the industry try to understand the differences they have because our main concern is the students. It is the university's mission to provide high quality education to the students. Thus, the cooperation from the industry is vital. It is hoped that the students will be given a proper job prospects during their industrial practical even though the duration is only 12 weeks. This is to ensure that the students get the real exposure of the working environment. As stated by Jiang \& Normah (2011), the students hoped to improve the training for graduate students and use their knowledge to industry and have more chance to join the experiment. The university cannot do this alone without the help of the industry. In short, a successful university industry-partnership between UMP and DRB-HICOM can help to produce knowledgeable and skilled engineer that is required by future industry in Malaysia.

\section{ACKNOWLEDGEMENTS}

We like to thank The Ministry of Higher Education for granting the FRGS grant to Normah Othman thus make it possible for us to conduct this research. We also wish to thank the Dean, Ex-Dean and lecturers from Faculty of Mechanical Engineering, Universiti Malaysia Pahang for participating in this research.

\section{REFERENCES}

[1] Blaug, S., Chien, C., \& Shuster, M. J. (2004). Managing innovation: university-industry partnerships and the licensing of the Harvard mouse. Nature Biotechnology, 22(6), 761-763.

[2] Jiang, C. C., \& Normah Othman. (2011). The Effect of Education Condition for the University-Industry Collaboration: A Case Study of Faculty Mechanical Engineering in UMP. Management Science and Engineering, 5(3), 169-174.

[3] Jones, L. M. (2012). University-Industrial Research Collaboration - Advantages of the Collaborative Relationships, Disadvantages of the Collaborative Relationships. Retrieved from

http://education.stateuniversity.com/pages/2519/University-I ndustrial-Research-Collaboration.html

[4] Normah Othman. (2011). Factors Contributing to the Effectiveness of a University-Industry Partnership. Sino-US English Teaching, 8(11), 681-688. 